\title{
CFRTP molding method of the three-dimensional shape by using direct resistance heating to carbon fiber
}

\author{
S. Enoki ${ }^{1}$, K. Moriito ${ }^{2}$, K. Tanaka ${ }^{2}$ \& T. Katayama ${ }^{2}$ \\ ${ }^{I}$ Department of Mechanical Engineering, \\ Nara National College of Technology, Japan \\ ${ }^{2}$ Department of Biomedical Engineering, Doshisha University, Japan
}

\begin{abstract}
Recently, Carbon Fiber Reinforced Thermoplastics (CFRTP) are expected to be used for lightweight component parts. To mold CFRTP, it is necessary to impregnate carbon fiber bundles with thermoplastic resin by heating the materials. We have been developing a low cost CFRTP molding technique in which direct resistance heating was applied to carbon fiber itself. When electrical current runs through the materials, they are heated by joule heat. Therefore this method can run with simple equipment and low consumed power. In our previous studies, flat plates and pipes of CFRTP have been molded by using direct resistance heating and the molding abilities have been evaluated. To use this molding method for automobile components, it is necessary to apply this method to three-dimensional molding. However, the temperature distribution of carbon fiber NCF has not been clarified when a direct resistance heating method is applied to three-dimensional molding. In this study, the heating properties of carbon fiber NCF formed at $90^{\circ}$ and $120^{\circ}$ by using direct resistance heating were evaluated, and angle plates were molded. By using direct heating to carbon fiber $\mathrm{NCF}$ the angle plates of $\mathrm{CF} / \mathrm{PA} 6$ have been successfully molded in the condition for the holding time of 1 minute, the pressure of $2 \mathrm{MPa}$ and heating temperature of $290^{\circ} \mathrm{C}$.

Keywords: carbon fiber, non-crimp fabric (NCF), Direct resistance heating, thermoplastics composites, molding.
\end{abstract}




\section{Introduction}

In the automobile industry, to consider the regulation of carbon dioxide emissions of the car, fuel economy improvement has been required as a countermeasure to these problems. One of the means is to reduce vehicle weight [1]. For the purpose of further weight reduction of cars, carbon fiber reinforced plastics (CFRP), which have higher specific strength and specific rigidity than conventional lightweight materials such as high strength steel and aluminum alloy, have been researched to replace heavy body structures made of metal [2]. However, due to their drawbacks such as time consuming process, high cost and low recyclability of thermosetting resins, CFRP have been used only for nonmass-produced cars.

Accordingly, in terms of productivity, in another world cost reduction, Carbon Fiber Reinforced Thermoplastics (CFRTP) which uses thermoplastic resin for the matrix, have attracted attentions. Since CFRTP are using thermoplastic resins that can be reshaped, they have more advantages in recyclability and productivity compared to CFRP. Therefore CFRTP are suitable for the mass-produced car parts [3]. In order to make effective use of mechanical properties of carbon fiber, it is necessary to use continuous fiber as a reinforcing material. Among fabrics using continuous fibers, there are non-crimp fabric (NCF) and woven fabric [4, 5]. Comparing these two fabrics, NCF has been reported to be superior in strength. By using NCF with non-woven resin efficient molding in terms of production cost and operability of materials can be realized [6].

For further cost reduction, it is required to improve and develop the molding process. In the molding of CFRTP, it is necessary to impregnate carbon fiber $\mathrm{NCF}$ with thermoplastic resin by heating. Direct resistance heating used in this study adopts a heating method using the resistance heating by direct energization to the material, so the equipment is simple and the production cost is not so high. When an electrical current runs through the materials, they are heated by joule heat. Therefore, molding by a small amount of power can be achieved. This heating method has been already applied for metal heating [7, 8] and CFRTP welding [9-12]. At present, in direct resistance heating, the molding of flat plates and tabular CFRTP has only been performed, and possibility of forming the three-dimensional shape has not been studied [13]. Establishment of CFRTP molding of three-dimensional shape is essential to the improvement in productivity of cars.

In this study, the direct resistance heating properties of the carbon fiber $\mathrm{NCF}$ in three-dimensional shape were evaluated and CFRTP molding of a threedimensional shape was conducted.

\section{Characteristics of direct resistance heating to angle carbon fiber NCF}

\subsection{Materials and experimental methods}

The non-crimp stitched carbon fabrics of $\left[0^{\circ} / 90^{\circ}\right]$ in the weight per unit area of $300 \mathrm{~g} / \mathrm{m}^{2}$, using PAN-based carbon fibers, were used. Specimens with dimensions 
of $100 \mathrm{~mm}$ in length and $25 \mathrm{~mm}$ in width were cut from this carbon fiber NCF. In CFRTP molding using direct resistance heating to the carbon fiber NCF, precise heating control of the shaped carbon fiber NCF is required. In this study, it is intended to clarify that how the angle carbon fiber NCF is heated. By using direct resistance heating to three-dimensional carbon fiber $\mathrm{NCF}$, temperature distribution of the carbon fiber NCF at the time of electric heating is measured so as to establish whether it is possible to heat the material to melting temperature of resins or not.

Figure 1 shows schematic drawing of temperature distribution measurement of a single NCF ply. It was shaped so as to bend at the center of the specimen and made experiments in the following two cases: the bending angles were $90^{\circ}$ and $120^{\circ}$. In addition, temperature distributions were measured at both surfaces of NCF $\left(0^{\circ}\right.$ layer and $90^{\circ}$ layer). $10 \mathrm{~mm}$ from both ends of carbon fiber NCF were fixed with clips and connected to the high-frequency power supply (T1626014AAH, THAMWAY, JAPAN) by using cables. The power was supplied to the carbon fiber NCF through the impedance converter (T010-6012A, THAMWAY, JAPAN). The conditions of energization were set as follows: frequency was $20 \mathrm{kHz}$ electricity was $250 \mathrm{~W}$ and impedance ratio was power: load $=9: 1$. Temperature distributions at the time when $0^{\circ}$ layer of carbon fiber NCF reached $250^{\circ} \mathrm{C}$ were observed by using infrared thermography (TVS-500, NEC Avio, JAPAN). For comparison, temperature distributions of flat carbon fiber NCF were also observed in the same way.

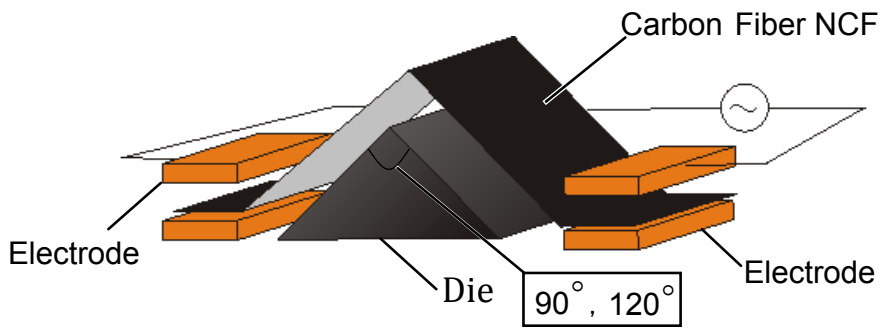

Figure 1: Schematic drawing of experimental setup for the temperature distribution measurement of single NCF ply.

Figure 2 shows schematic drawings of temperature history measurement of $\mathrm{NCF}$ laminates for $\left[0^{\circ} / 90^{\circ}\right]_{\mathrm{S}},\left[0^{\circ} / 90^{\circ}\right]_{2}$ and $\left[90^{\circ} / 0^{\circ}\right]_{\mathrm{S}}$. Direct resistance heating was performed in the same way as the temperature distribution measurement for a single ply. K-type thermocouple was attached in the middle of laminated NCF for each laminate and temperature recorded per second with graphic recorder (OMRON Co. Ltd., Japan). For the real molding of CFRTP, resin sheets are sandwiched between each layer of the NCF. In order to simulate CFRTP molding, Teflon sheets, which have heat resistance and insulation properties, were sandwiched between each of the NCF instead of resin sheet in this experiment. 


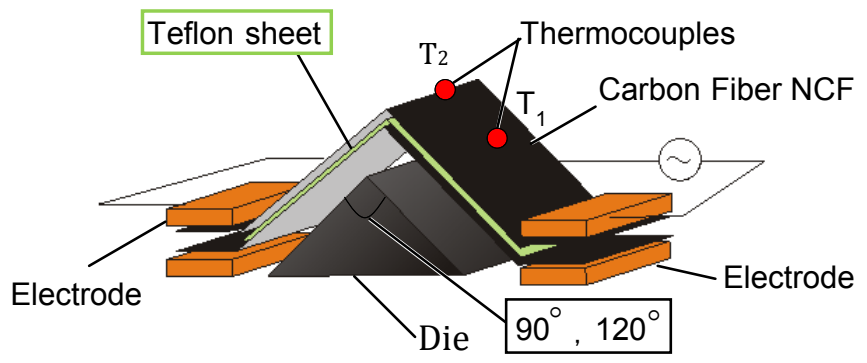

Figure 2: Schematic drawing of experimental setup for the measurement of temperature history for $\left[0^{\circ} / 90^{\circ}\right]_{\mathrm{S}},\left[0^{\circ} / 90^{\circ}\right]_{2}$ and $\left[90^{\circ} / 0^{\circ}\right]_{\mathrm{S}}$ laminates.

\subsection{Results and discussions}

Figures 3 and 4 show the temperature distribution of $0^{\circ}$ layer and $90^{\circ}$ layer of the single NCF ply respectively. Direct resistance heating could heat carbon fiber $\mathrm{NCF}$ to $250^{\circ} \mathrm{C}$. However, the temperature of the bended area was low compared to other area in both cases of $90^{\circ}$ angle and $120^{\circ}$ angle NCF.

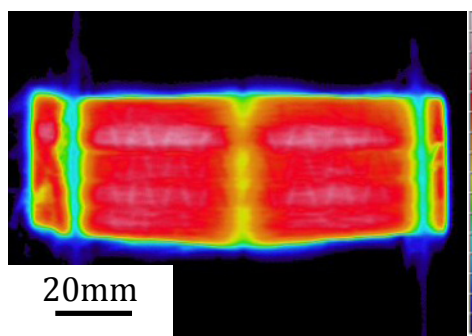

(a) $90^{\circ}$ angle $\mathrm{NCF}$

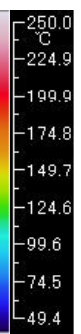

$-49.4$

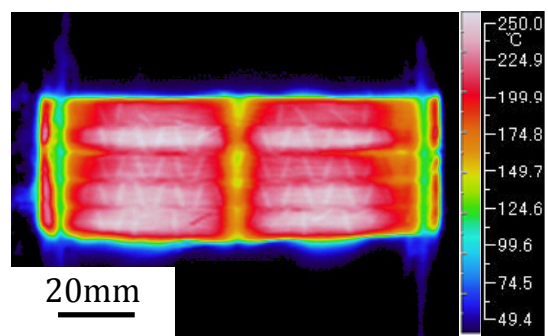

(b) $120^{\circ}$ angle $\mathrm{NCF}$

Figure 3: Temperature distribution of NCF's $0^{\circ}$ orientation for a single NCF ply.

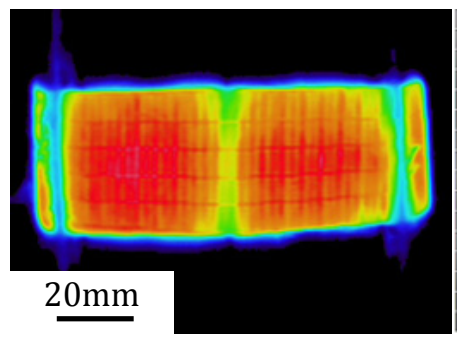

(a) $90^{\circ}$ angle $\mathrm{NCF}$

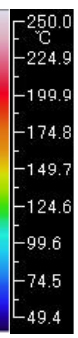

$-49.4$

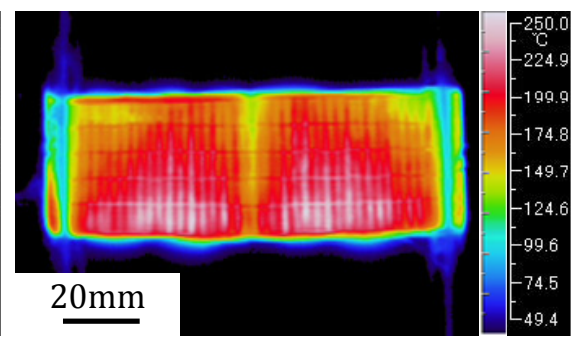

(b) $120^{\circ}$ angle NCF

Figure 4: Temperature distribution of NCF's $90^{\circ}$ orientation for a single NCF ply. 
Figure 5 shows the temperature history of the laminated $90^{\circ}$ angle carbon fiber NCF which was laminated in $\left[0^{\circ} / 90^{\circ}\right]_{\mathrm{S}},\left[0^{\circ} / 90^{\circ}\right]_{2}$ and $\left[90^{\circ} / 0^{\circ}\right]_{\mathrm{S}}$ and heated by using direct resistance heating. In the case of $120^{\circ}$ angle NCF, the differences of the temperature between the flat area $\left(\mathrm{T}_{1}\right)$ and the bended area $\left(\mathrm{T}_{2}\right)$ of $\left[0^{\circ} / 90^{\circ}\right]_{\mathrm{S}}$, $\left[0^{\circ} / 90^{\circ}\right]_{2}$ and $\left[90^{\circ} / 0^{\circ}\right]_{\mathrm{S}}$ were $10.4^{\circ} \mathrm{C}, 13.6^{\circ} \mathrm{C}$ and $11.85{ }^{\circ} \mathrm{C}$ respectively. In the case of the single carbon fiber NCF ply (shown in Figs 3 and 4), the temperature difference was $124^{\circ} \mathrm{C}$ for $120^{\circ}$ angle NCF. By laminating NCF, the temperature difference at different fiber orientation was reduced and showing uniform heating.

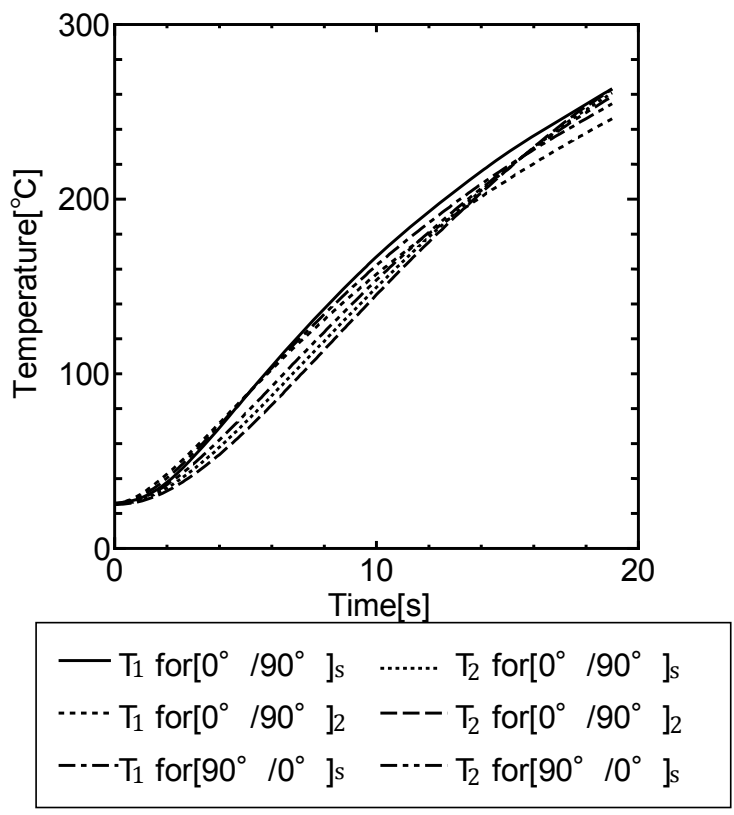

Figure 5: Temperature history of laminated NCF $\left[0^{\circ} / 90^{\circ}\right]_{\mathrm{S}},\left[0^{\circ} / 90^{\circ}\right]_{2}$ and $\left[90^{\circ} / 0^{\circ}\right]_{\mathrm{s}}\left(120^{\circ}\right.$ angle $\left.\mathrm{NCF}\right)$.

\section{CFRTP molding for the three-dimensional shape}

\subsection{Materials and experimental methods}

The same non-crimp stitched carbon fabrics of $\left[0^{\circ} / 90^{\circ}\right]$ shown in section 2 were used for reinforcement and the non-woven resins of PA6 (Ube Industries, Ltd) in the weight per unit area of $50 \mathrm{~g} / \mathrm{m}^{2}$ were used. Lamination structure of the intermediate substrate was $\left[0^{\circ} / 90^{\circ}\right] \mathrm{s}$ and fiber volume fraction was set to $50 \%$. Figure 6 shows schematic drawing of CFRTP molding. Specimens were heated 
by the same method as described in section 2. Table 1 shows the molding conditions. Precision universal tester (AUTOGRAPH AG-100kN, Shimadzu Corporation) was used for applying molding pressure. The material was pressurized after holding the target temperature for 60 seconds, then the materials was cooled down by natural cooling. During molding process, temperature history was recorded at measuring time interval of 0.1 second.

A cross section of the molded specimen was observed by Laser microscope (OPLETICS-H1200, Lasertec) to evaluate the impregnation of resins to the carbon fiber NCF.

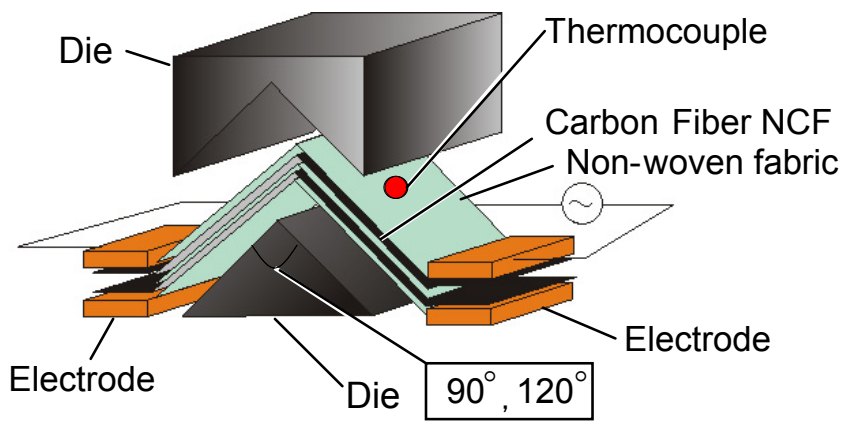

Figure 6: Schematic drawing of CFRTP molding.

Table 1: Molding conditions.

\begin{tabular}{|c|c|c|c|c|}
\hline \multirow{2}{*}{ Specimen } & Pressure & Temperature & Holding time & Molding angle \\
\cline { 2 - 3 } & {$[\mathrm{MPa}]$} & {$\left[{ }^{\circ} \mathrm{C}\right]$} & {$[\mathrm{s}]$} & {$\left[{ }^{\circ}\right]$} \\
\hline CF/PA-2(250) & 2 & 250 & \multirow{2}{*}{60} & \\
\hline CF/PA-1 & 1 & \multirow{2}{*}{290} & 60,120 \\
\hline CF/PA-2 & 2 & & & \\
\hline
\end{tabular}

\subsection{Results and discussions}

Figure 7 shows temperature history of molding an angle plate. Including heating and cooling time, molding was completed in around 200 seconds. For a $90^{\circ}$ angle plate, it takes longer time than a $120^{\circ}$ angle plate. Figures 8-10 show the cross-sectional observation images of CF/PA-2 (250), CF/PA-1 and CF/PA-2. For CF/PA-2 (250), the layer of resin remains in a center. Since the melt viscosity of PA6 decreases as the temperature increases, the temperature of $250^{\circ} \mathrm{C}$ is not 


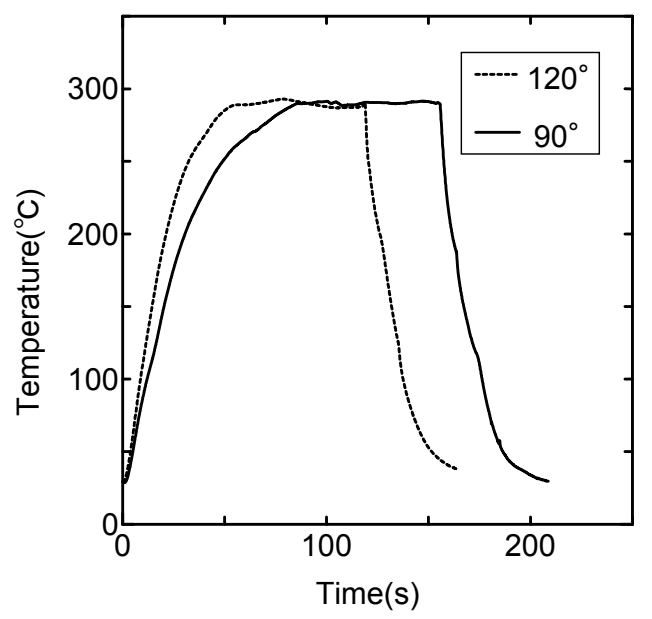

Figure 7: Temperature history of molding angle plates.

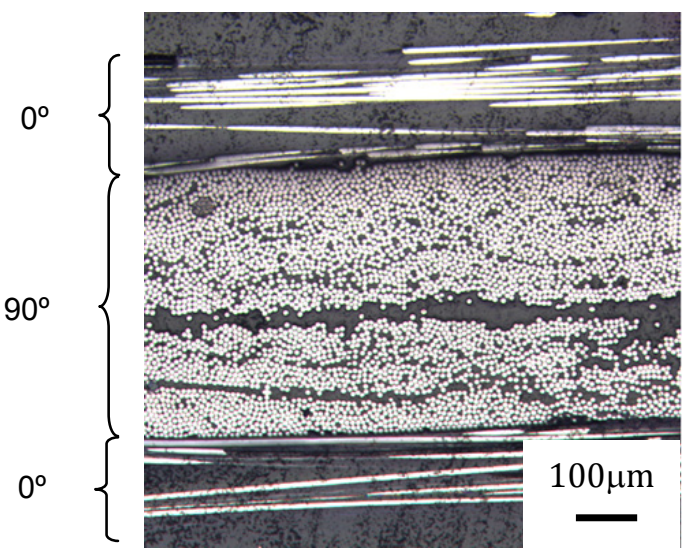

Figure 8: Microscope observation of cross section of molded specimen (CF/PA-2(250)).

enough to mold this material (as shown in Fig. 8). Under the pressure of $2 \mathrm{MPa}$ and temperature of $290^{\circ} \mathrm{C}$, good impregnated specimen was observed (as shown in Fig. 10). The angle plates of CF/PA6 was successfully molded in 200 seconds by using direct heating to carbon fiber NCF in the condition for the pressure of $2 \mathrm{MPa}$ and heating temperature of $290^{\circ} \mathrm{C}$. 


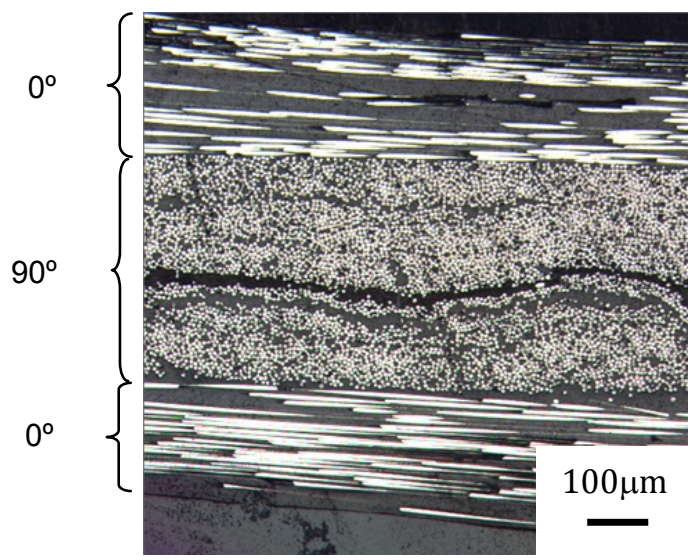

Figure 9: Microscope observation of cross section of molded specimen (CF/PA-1).

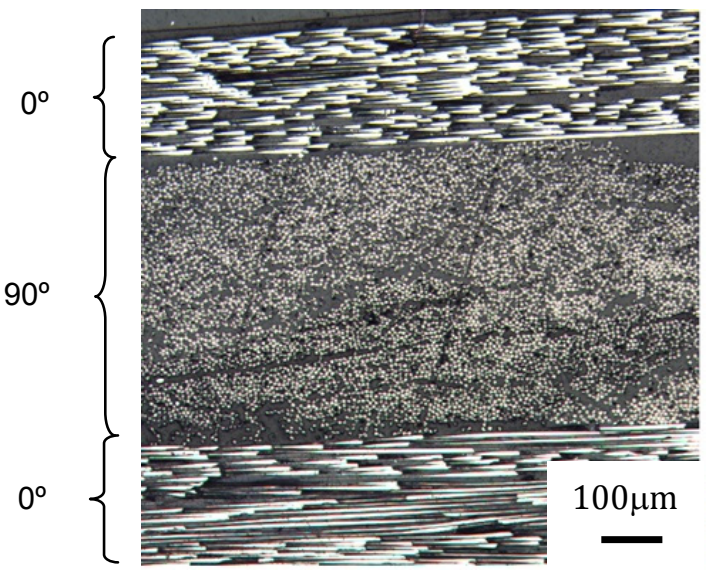

Figure 10: Microscope observation of cross section of molded specimen (CF/PA-2).

\section{Conclusions}

The direct resistance heating properties of the single carbon fiber NCF ply and laminated carbon fiber NCF was revealed. The angle plates of CF/PA6 was successfully molded in 200 seconds by using direct heating to carbon fiber NCF in the condition for the pressure of $2 \mathrm{MPa}$ and heating temperature of $290^{\circ} \mathrm{C}$. 


\section{Acknowledgements}

This work was partially supported by a research project on "Research and Development Center for Advanced Composite Materials" of Doshisha University and MEXT (the Ministry of Education, Culture, Sports, Science and Technology, Japan) - Supported Program for the Strategic Research Foundation at Private Universities, 2013-2017, the project S1311036.

\section{References}

[1] Y. Daisho, Perspectives on Future Motor Vehicle Technologies Associated with Environment and Energy, IATSS Review, Vol.33, No. 3, 51-56, 2008.

[2] R. Shida, K. Tsumuraya., S. Nakatsuka, \& J. Takahashi, Effect of automobile lightening by CFRP on the world energy saving, The Ninth Japan International SAMPE symposium, 8-13, 2005.

[3] J.R. Duflou, J. De Moor, I. Verpoest, W. Dewulf, Environmental impact analysis of composite use in car manufacturing, Manufacturing Technology, Vol. 58, 9-12, 2009

[4] B.C. Meyer, Ch.V. Katsiropoulos \& Sp.G. Pantelakis, Hot forming behavior of non-crimp fabric peek/c thermoplastics composites, Composites Structures, Vol. 90, 225-232, 2009.

[5] G.A. Bibo, P.J. Hogg, R. Backhouse \& A. Mills, Carbon-Fibre Non-Crimp Fabric Laminates for Cost-Effective Damage-Tolerant Structures, Composites Science and Technology, Vol. 58, 129-143 1998.

[6] K. Tanaka, T. Katayama \& K. Uno, Eco-efficient Manufacturing Process of Fibre Reinforced Thermoplastic, WIT Transactions on the Built Environment, Vol. 97, pp. 203-210.

[7] J. Yanagimoto \& R. Izumi, Continuous electric resistance heating -Hot forming system for high-alloy metals with poor workability, Journal of Materials Processing Technology, Vol. 209, 3060-3068, 2009.

[8] S. Maki, M. Ishiguro, K. Mori \& H. Makino, Thermo-mechanical treatment using resistance heating for production of fine grained heattreatable aluminium alloy sheets, Journal of Materials Processing Technology, Vol. 177, 444-447, 2006.

[9] D. Stavrov \& H.E.N. Bersee, Resistance welding of thermoplastic composites-an overview, Composites: Part A 36, 39-54, 2005.

[10] M. Hou, M. Yang, A. Beehag, Y.W. Mai \& L Ye, Resistance welding of carbon fibre reinforced thermoplastic composite using alternative heating element, Composite Structure, Vol. 47, 667-672, 1999.

[11] C. Ageorges, L. Ye, M. Hou, Experimental investigation for the resistance welding for thermoplastic-matrix composites. Part 1: heating element and heat transfer Composites Science and Technology, Vol. 60, 1027-1039, 2000. 
282 High Performance and Optimum Design of Structures and Materials

[12] Christophe Ageorges, Lin Ye \& M. Hou, Experimental investigation for the resistance welding for thermoplastic-matrix composites. Part 2: optimum processing window and mechanical performance, Composites Science and Technology, Vol. 60, 1191-1202, 2000.

[13] S. Enoki, K. Iwamoto, R. Harada, K. Tanaka \& T. Katayama, Heating properties of carbon fibers by using direct resistance heating, WIT Transactions on the Built Environment, Vol. 124, 239-248, 2012. 